\title{
Bilateral Brachial Artery Aneurysms with Distal Embolisms in a Patient with Prolonged Crutch Compression
}

\author{
Baran Simsek $^{1}$, Orkut Guclu ${ }^{2}$, Serhat Huseyın ${ }^{2}$, and Volkan Yuksel ${ }^{2}$ \\ Department of Cardiovascular Surgery, Medicana International Hospital, İstanbul, ${ }^{2}$ Department of Cardiovascular Surgery, Trakya \\ University School of Medicine, Edirne, Turkey
}

\begin{abstract}
Chronic axillary crutch use may lead to axillary or brachial artery aneurysms and associated axillobrachial thromboembolic complications. Most of these aneurysms remain asymptomatic and undiagnosed until a complication occurs. Early diagnosis and appropriate surgical management of the aneurysms is required for a favorable outcome. We report a case of bilateral brachial artery aneurysms with left radial and ulnar artery embolisms in a patient who had been using crutches for 33 years due to a congenital skeletal anomaly.
\end{abstract}

Key Words: Brachial artery, Aneurysm, Crutches, Blood vessel prosthesis, Embolism
Received July 13, 2021

Revised September 20, 2021

Accepted December 2, 2021

Published on December 31, 2021

Corresponding author: Baran Simsek Department of Cardiovascular Surgery, Medicana International Hospital, Beylikduzu Str no. 3, İstanbul 34520, Turkey

Tel: 90-505 6972139

Fax: 90-2128677500

E-mail: simsekbaran@yahoo.com https://orcid.org/0000-0002-9554-9498

Copyright (c) 2021 The Korean Society for Vascular Surgery

This is an Open Access article distributed under the terms of the Creative Commons Attribution Non-Commercial License (http://creativecommons.org/licenses/by-nc/4.0) which permits unrestricted non-commercial use, distribution, and reproduction in any medium, provided the original work is properly cited.

Cite this article; Vasc Specialist Int 2021. https://doi.org/10.5758/vsi.210052

\section{INTRODUCTION}

Cardiac embolism is the most common cause of acute peripheral arterial occlusion. In the presence of an arterial aneurysm, mural thrombus of the aneurysm wall is frequently the main source of distal thromboembolism [1]. Axillary crutches, which are widely used by patients with congenital or acquired gait disorders, may be the most specific and common reason for upper extremity thromboembolism due to axillobrachial artery aneurysm (ABAA) formation by repetitive trauma [2]. We report a case of bilateral $A B A A s$ with left radial and ulnar artery embolisms in a patient who had been using crutches for 33 years due to a congenital skeletal anomaly. IRB approval was waived due to the retrospective case report.

\section{CASE}

A 48-year-old female was admitted to our clinic due to sudden-onset left forearm pain which had begun 3 days before and gradually worsened. The patient had no history of heart disease or arrhythmia. She had a congenital skeletal anomaly in her medulla spinalis and bilateral lower extremities and had been using crutches for 33 years. On physical examination, there was no pulse in the left brachial, ulnar, or radial arteries. The axillary artery pulse was normal in the axillary fossa, and a $4 \mathrm{~cm} \times 5 \mathrm{~cm}$ pulsatile mass was palpable on the medial aspect of the left arm. The neurological examination did not reveal any abnormalities in the left arm. Cardiac auscultation and electrocardiography demonstrated a spontaneous sinus rhythm. Transthoracic echocardiography did not show a cardiac thrombus. Computed tomography angiography showed a $4 \mathrm{~cm} \times 5 \mathrm{~cm}$ left brachial artery aneurysm (Fig. 1). The radial and ulnar arteries showed ear- 


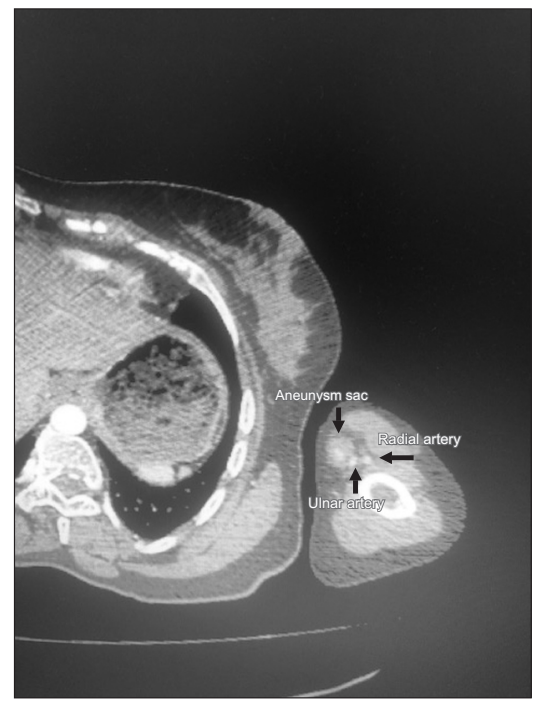

Fig. 1. Axial computed tomography angiography image of the left brachial artery aneurysm.

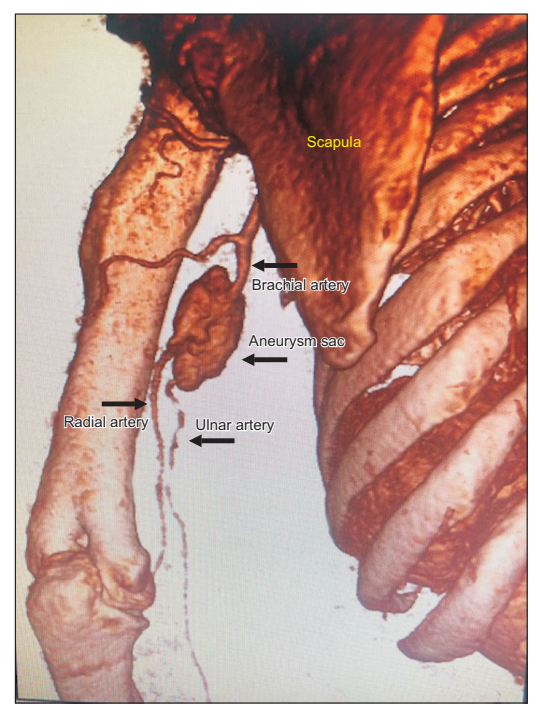

Fig. 2. Posterior view of 3-dimensional computed tomography angiography showed the left brachial artery aneurysm and early bifurcation of the radial and ulnar arteries.

ly bifurcation just below the aneurysm (Fig. 2). A $3 \mathrm{~cm} \times 4.5$ $\mathrm{cm}$ aneurysm in the contralateral brachial artery in the midupper arm without mural thrombus was also present (Fig. 3). The aneurysm sacs were located in the area that was directly compressed by both crutches. Under general anesthesia, a longitudinal incision was created over the mass in the medial aspect of the left arm. A 5-cm fusiform aneurysm of the left brachial artery was dissected (Fig. 4). Proximal and distal controls were obtained after heparin administration. The aneurysm sac was resected. Radial and ulnar arterial thromboembolectomy was performed with a 3-Fr Fogarty

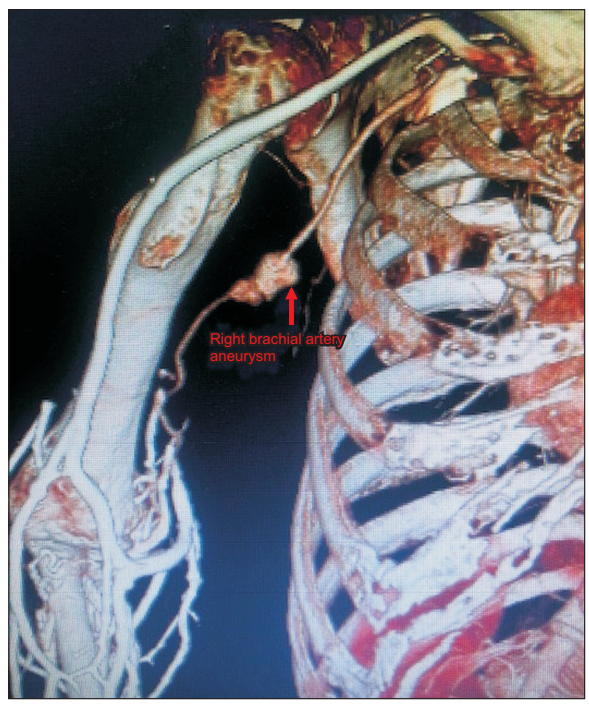

Fig. 3. Anterior view of 3-dimensional computed tomography angiography showed asymptomatic right brachial artery aneurysm.

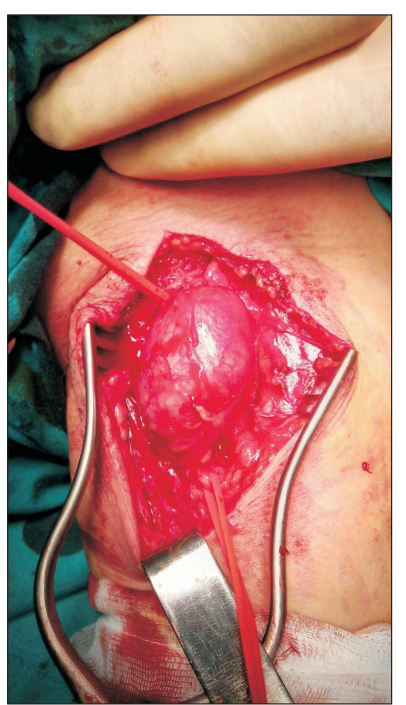

Fig. 4. Intraoperative photography showed a fusiform aneurysm of the left brachial artery.

arterial embolectomy catheter (Edwards Lifesciences, Irvine, CA, USA). Finally, an interposition graft was performed with a 4-mm Propaten heparin-bonded graft (W.L. Gore \& Associates Inc., Flagstaff, AZ, USA) using 6-0 polypropylene sutures. The quality and diameter of both great saphenous veins were inadequate due to the anomalies and deformities of the lower extremities. Postoperative anticoagulants were given with intravenous heparin converted to warfarin. The postoperative course was uneventful and the patient was discharged on the third postoperative day with warfarin and aspirin. Warfarin was discontinued after six months. 
Follow-up duplex ultrasonography after 1 year showed patent graft and normal radial and ulnar arterial flow.

\section{DISCUSSION}

Upper extremity arterial aneurysms are an uncommon form of peripheral artery aneurysm [3]. Often, ABAAs develop due to arterial degeneration which occurs secondary to repetitive blunt or penetrating trauma, such as repetitive overhead motion during athletic activities and chronic crutch use. With the increasing use of axillary crutches, a frequent crutch-induced ABAA formation is expected. They may also develop due to degenerative processes, atherosclerosis, thoracic outlet syndrome, infection, and collagen vascular diseases [4]. Patients using axillary crutches can develop thrombosis, distal embolization, pressure symptoms, and rupture. Treatments for ABAAs include resection and reconstruction, stent grafts, or exclusion and bypass surgery. We performed resection and interposition grafting in our case because of the poor quality of the vein graft. Using a vein graft as a conduit has a better patency rate than a prosthetic graft [5]. Thromboembolectomy must be performed before completion of the distal anastomosis, as the distal run-off is the most important factor in graft patency. As in our case, there should be anatomic variations of the upper extremity arteries. Therefore, computed tomography angiography or digital subtraction angiography must be performed before the surgery. Thrombogenesis, distal embolization, or rupture may be caused by ABAAs. Inadequate treatment causes permanent disability, limb loss, or even acute hypovolemic complications secondary to exsanguination, which can potentially cause death [6]. Early diagnosis and appropriate surgical management of the aneurysm is required for favorable outcomes. Axillobrachial arterial complications are commonly associated with pressure from the axillary bar. Improper crutch fitting is also a contributing factor for axillobrachial arterial complications. Appropriate crutch fitting and gait training are crucial to prevent crutch-related injuries. Axillary crutches that are too long will likely accentuate pressure on the axillary structures. The axillary bar should be set at 77\% of the patient's height [7], or at the level of the patient's height minus $40 \mathrm{~cm}$ [8]. Joyce and Kirby [9] recommended that there be $5 \mathrm{~cm}$ between the anterior axillary fold and the axillary bar. Potter and Wallace [10] suggested that when standing with the feet together and crutch tips 8 to $10 \mathrm{~cm}$ lateral to the feet, there should be 2 to 3 finger breadths of space between the patient's axilla and the axillary bar. To reduce the risk of injury, patients should be instructed to bear weight through the hands with their elbows extended [11]. After surgery, the patient should switch to forearm crutches; temporary axillary crutch use should be avoided if possible. Wheelchairs should be used in such complicated patients in the early postoperative period. Our patient used a wheelchair for eight weeks after the operation, and then ambulated with forearm crutches.

\section{FUNDING}

None.

\section{CONFLICTS OF INTEREST}

The authors have nothing to disclose.

\section{ORCID}

\author{
Baran Simsek \\ https://orcid.org/0000-0002-9554-9498 \\ Orkut Guclu \\ https://orcid.org/0000-0001-6460-3175 \\ Serhat Huseyın \\ https://orcid.org/0000-0003-4118-040X \\ Volkan Yuksel \\ https://orcid.org/0000-0001-9518-2588
}

\section{AUTHOR CONTRIBUTIONS}

Concept and design: BS. Analys is and interpretation: BS. Data collection: BS, OG. Writing the article: BS. Critical revision of the article: $0 \mathrm{G}, \mathrm{SH}, \mathrm{VY}$. Final approval of the article: all authors. Statistical analysis: none. Obtained funding: none. Overall responsibility: BS.

\section{REFERENCES}

1) Aufderheide TP. Peripheral arteriovascular disease. In: Rosen P, Barkin R, Danzl DF, editors. Emergency medicine: concepts and clinical practice. 4th ed. St. Louis: Mosby; 1998. p. 1826-1844.

2) Todd GJ, Benvenisty Al, Hershon S, Bigliani LU. Aneurysms of the mid ax- illary artery in major league baseball pitchers--a report of two cases. J Vasc Surg 1998;28:702-707.

3) Schrijver AM, De Borst GJ, Van Her- 
waarden JA, Vonken EJ, Moll FL, Vos $\mathrm{JA}$, et al. Catheter-directed thrombolysis for acute upper extremity ischemia. J Cardiovasc Surg (Torino) 2015;56:433-439.

4) Malik MK, Kraev Al, Hsu EK, Clement $\mathrm{MH}$, Landis GS. Spontaneous axillary artery aneurysm: a case report and review of the literature. Vascular 2012;20:46-48.

5) McCarthy WJ, Flinn WR, Yao JS, Williams LR, Bergan JJ. Result of bypass grafting for upper limb ischemia. J Vasc Surg 1986;3:741-746.

6) Lind RC, de Vries M, Rolink R, Oskam $\mathrm{J}$, Pierie ME. Images in vascular medicine. Surgical management of an isolated symptomatic true axillary artery aneurysm. Vasc Med 2013;18:145-146.

7) Bauer DM, Finch DC, McGough KP, Benson CJ, Finstuen K, Allison SC. A comparative analysis of several crutch-length-estimation techniques. Phys Ther 1991;71:294-300.
8) Beckwith JM. Analysis of methods of teaching axillary crutch measurement. Phys Ther 1965;45:1060-1065.

9) Joyce BM, Kirby RL. Canes, crutches and walkers. Am Fam Physician 1991;43:535-542.

10) Potter BE, Wallace WA. Crutches. BMJ 1990;301:1037-1039.

11) Goh JC, Toh SL, Bose K. Biomechanical study on axillary crutches during single-leg swing-through gait. Prosthet Orthot Int 1986;10:89-95. 